\title{
NOTIZEN
}

\section{Röntgenkleinwinkel-Untersuchungen von nitrierten Faserkeratinen}

\section{SPEI}

Deutsches Wollforschungsinstitut an der Technischen Hochschule Aachen

(Z. Naturforsch. 25 b, 420 [1970]; eingegangen am 19. Februar 1970)

Vor einiger Zeit berichteten KRATKY et al. ${ }^{1}$ in dieser Zeitschrift, daß auf den Röntgenkleinwinkel-Diagrammen von nitrierten Roßhaarproben eine Kontraktion der 2., 3. und 4. Ordnung der axialen $190 \AA$ \& Periodizität von $7 \%$ auftrat. In der Zwischenzeit haben VALLEE et al. ${ }^{2}$ Tetranitromethan als schonendes Nitrierungsagens in die Enzymchemie eingeführt und eine Mononitrierung der Tyrosinreste ohne Zersetzung der Enzyme gefunden. Deshalb sollte dieses Nitrierungsverfahren auch bei Faserproteinen angewandt werden, um zu sehen, ob unter diesen schonenden Bedingunen auch schon Veränderungen auf den entsprechenden Kleinwinkeldiagrammen auftraten. Außerdem sollte Mohair bei diesen Untersuchungen verwendet werden, da Mohair das schärfste Faserdiagramm von allen Faserkeratinen liefert.

Hierzu wurden $0,1 \mathrm{ml}$ Tetranitromethan in $1 \mathrm{ml}$ absolutem Äthanol gelöst und in $50 \mathrm{ml}$ 0,05-m. Trispuffer von $\mathrm{pH} 8$ gegeben. In dieser Lösung wurden $0,2 \mathrm{~g}$ Mo-

\begin{tabular}{|c|c|c|c|}
\hline $\begin{array}{c}\mathrm{HNO}_{3} \text {-Konz. } \\
{[-n .]}\end{array}$ & $\begin{array}{l}\text { Reaktions- } \\
\text { zeit [h] }\end{array}$ & $\begin{array}{c}\text { Temperatur } \\
{\left[{ }^{\circ} \mathrm{C}\right]}\end{array}$ & $\begin{array}{l}\text { Änderung } \\
\text { im Diagramm }\end{array}$ \\
\hline 0,5 & 20 & 40 & 7. Ordnung verstärkt \\
\hline 1,0 & 8 & 60 & $\begin{array}{l}\text { 6., 7. und } 8 . \text { Ordnung } \\
\text { verstärkt }\end{array}$ \\
\hline 1,5 & 20 & 60 & $\begin{array}{l}\text { 6. und } 8 \text {. Ordnung } \\
\text { verstärkt; } \\
\text { 7. Ordnung sehr } \\
\text { schwach } \\
\text { Ein schwacher } 198 \AA \\
\text { Reflex wird beobachtet }\end{array}$ \\
\hline 2,0 & 20 & 60 & $\begin{array}{l}\text { Fast alle Meridian- } \\
\text { reflexe abwesend; } \\
\text { 3. Ordnung nicht } \\
\text { mehr photometrisch } \\
\text { auswertbar }\end{array}$ \\
\hline
\end{tabular}

Tab. 1. Reaktionsbedingungen und Ergebnisse von nitrierten Mohairproben.

1 O. Kratky, A. Sekora, H. Zahn u. E. R. Fritze, Z. Naturforsch. 10 b, 68 [1955]

2 M. Sokolovsky, J. F. Riordan u. B. L. Vallee, Biochem. J. 5, 3582 [1966]. hair $48 \mathrm{~h}$ bei Raumtemperatur unter Rühren behandelt. Dann wurde die Probe abgesaugt, gewaschen und anschließend $24 \mathrm{~h}$ mit Äthanol extrahiert. Es zeigte sich, daß bei der Tetranitromethan-Behandlung ein Drittel des Tyrosins dinitriert, ein Drittel mononitriert und ein Drittel nicht nitriert worden war (vgl. auch BEYER und SCHENK ${ }^{3}$ ). Diese nitrierte Mohairprobe ergab ein scharfes, nahezu unverändertes Röntgendiagramm: alle Reflexe waren mit unveränderter Intensität vorhanden, und keine Langperiode war kontrahiert worden. Deshalb wurde Mohair zusätzlich auch noch mit verdünnten Salpetersäure-Lösungen nitriert, um zu sehen, ob hier der Kontraktionseffekt auftrat. Die wichtigsten Ergebnisse mit den entsprechenden Versuchsbedingungen sind in Tab. 1 zusammengestellt.

Auf keinem Diagramm konnte eine Kontraktion der 3. Ordnung festgestellt werden. Wenn die Proben aber anschließend $18 \mathrm{~h}$ bei Raumtemperatur mit einer $0,2-n$. Natrium-Decylsulfat-Lösung von $\mathrm{pH} 2$ behandelt wurden, beobachtete man auf den Diagrammen der beiden letzten Proben eine Kontraktion der 3. Ordnung von $66 \AA$ auf 63 bzw. $61 \AA$. Der Cystingehalt $(\mathrm{SS}+\mathrm{SH})$ dieser beiden Proben betrug 240 bzw. $142 \mu \mathrm{Mol} / \mathrm{g}$ im Vergleich zu $515 \mu \mathrm{Mol} / \mathrm{g}$ im unbehandelten Mohair. Bemerkenswert ist, daß auf dem Diagramm der letzten Probe die 3. Ordnung nach der Tensidbehandlung wieder photometrisch ausgewertet werden konnte. Die Kontraktion der 3. Ordnung scheint nur bei einem sehr ,gezielten" Cystinabbau kurz vor der gänzlichen Zerstörung der Faserstruktur aufzutreten. KRATKY et al. ${ }^{1}$ beschrieben den Effekt bei einer Roßhaarprobe, die $24 \mathrm{~h}$ bei $90{ }^{\circ} \mathrm{C}$ mit einer $0,15-n$. Salpetersäure-Lösung nitriert worden war. Als der Versuch mit Pferdemähnenhaar wiederholt wurde, waren auf dem entsprechenden Kleinwinkeldiagramm bereits alle Meridianreflexe verschwunden, während bei Pferdeschweifhaar noch keine Reflexkontraktion eingetreten war. Wenn Pferdeschweifhaar unter den gleichen Bedingungen aber $26,25 \mathrm{~h}$ behandelt worden war, wurde auf den entsprechenden Diagrammen eine kontrahierte, sehr schwache 3. Ordnung bei $59 \AA$ beobachtet.

Herrn Prof. Dr.-Ing. H. ZAHN danke ich für sein Interesse, Herrn Dr. H. Klostermeyer für die Aminosäurenanalyse, Herrn Dipl.-Chem. H. KnitTel für die Cystinanalysen und Frl. A. Augenadel für ihre Mitarbeit. Die Untersuchungen wurden dankenswerterweise vom amerikanischen Landwirtschaftsministerium unterstützt.

${ }^{3}$ H. Beyer u. U. Schenk, Kolloid-Z. u. Z. Polymere 233, 890 [1969]. 